\title{
CONSIDERAÇÕES ACERCA DO DEBATE DA EDUCAÇÃO AMBIENTAL PRESENTE HISTORICAMENTE NAS CONFERÊNCIAS AMBIENTAIS INTERNACIONAIS
}

\author{
CONSIDERATIONS ABOUT THE DEBATE OF THE ENVIRONMENTAL EDUCATION PRESENT \\ HISTORICALLYATTHE INTERNATIONAL ENVIRONMENTAL CONFERENCES \\ CONSIDERACIONES SOBRE EL DEBATE DE LA EDUCACIÓN AMBIENTAL EXISTENTE \\ HISTÓRICAMENTE EN LAS CONFERENCIAS INTERNACIONALES DEL MEDIO AMBIENTE
}

Fabio Luiz Leonel Queiroz

Mestre em Geografia pela UFMS-CPTL; Professor da rede pública de ensino de Mato Grosso do Sul. Integrante do "Observatório da Educação" (OBEDUC-UEMS) e do "Grupo de Estudos e Pesquisas em Práxis Educacional" (GEPPE-UEMS). E-mail: fllqueiroz@gmail.com.

\section{Rodrigo Simão Camacho}

Doutor em Geografia pela FCT-UNESP; Professor da Licenciatura em Educação do Campo (LEDUC) da Faculdade Intercultural Indígena (FAIND) na Universidade Federal da Grande Dourados (UFGD).

E-mail: rogeo@ymail.com.

\begin{abstract}
RESUMO
A preocupação com as questões ambientais envolvem todas as pessoas e todas as sociedades, desde aquelas mais desenvolvidas às mais arcaicas. A principal característica da evolução do movimento ambientalista se materializa por meio da prática da Educação Ambiental. Buscamos com o presente trabalho apresentar algumas considerações sobre a evolução do debate da Educação Ambiental presente nas conferências ambientais. Este artigo se desenvolveu a partir de pesquisa bibliográfica, por meio de leituras relacionadas ao tema de Educação Ambiental, e pela análise de documentos responsáveis por nortear o movimento ambientalista contemporâneo. Conclui-se que o grande avanço acerca das preocupações ambientais e por consequência, do movimento ambientalista materializou-se na segunda metade do século $X X$, no pós-segunda guerra mundial, principalmente por meio dos seguintes eventos - Conferência de Estocolmo, Conferência de Belgrado, Conferência de Tbilisi, Conferência de Moscou, Conferência de Jomtien, Conferência do Rio de Janeiro, Conferência de Nova Delhi, Conferência de Thessaloniki, Conferência de Quioto e Conferência Rio + 20. No entanto, a mais relevante de todas essas conferências foi a Conferência de Estocolmo, realizada em 1972, por apresentar-se como um rompimento de barreiras, tornando-se um grande avanço nas questões ambientais mundiais, reconhecida até os dias atuais.
\end{abstract}

Palavras-chave: Conferências Ambientais. Educação Ambiental. Questão Ambiental. 


\section{ABSTRACT}

The preoccupation with environmental question involve all people and all societies, from those more developed to the most archaic. The main feature of the evolution of the environmental movement is embodied through the practice of environmental education. We seek in this paper to present some considerations on the development of the debate of environmental education present in environmental conferences. This article was developed from literature through readings related to the theme of environmental education. The analysis of the documents responsible for guiding the contemporary environmental movement. It is concluded that the breakthrough of the environmental concerns and therefore the environmental movement materialized in the second half of the twentieth century, in the post-World War II, mainly through the following events - Stockholm Conference, Belgrade Conference, Conference of Tbilisi, Moscow Conference, Jomtien Conference, the Rio de Janeiro Conference, New Delhi Conference, Thessaloniki Conference, the Kyoto Conference and Rio +20 . However, the most significant of all these conferences was the Stockholm Conference in 1972 by present as a break barriers, making it a major breakthrough in global environmental issues, recognized to this day.

Keywords: Environmental Conferences. Environmental Education. Environmental Question.

\section{RESUMEN}

La preocupación por las cuestiones ambientales involucran todas las personas y todas las sociedades, desde las que más ha desarrollado el más arcaico. La principal característica de la evolución del movimiento ambiental se materializa a través de la práctica de la educación ambiental. Buscamos con este trabajo presentar algunas consideraciones sobre la evolución del debate sobre la educación ambiental a través de las conferencias ambientales. Este artículo fue desarrollado a partir de la literatura, a través de lecturas relacionadas con el tema de la educación ambiental, y el análisis de los documentos encargados de guiar el movimiento ambiental contemporáneo. Llegamos a la conclusión de que el avance en las preocupaciones ambientales y, por lo tanto, el movimiento ambientalista, se materializó en la segunda mitad del siglo XX, después de la Segunda Guerra Mundial, principalmente a través de los siguientes eventos Conferencia de Estocolmo, Conferencia de Belgrado, Conferencia de Tbilisi, Conferencia de Moscú, Conferencia de Jomtien, Conferencia de Río de Janeiro, Conferencia de Nueva Delhi, Conferencia de Tesalónica, Conferencia de Kyoto y Conferencia Río + 20. Sin embargo, la más importante de todas estas conferencias fue la Conferencia de Estocolmo, retenida en 1972, por presentar-se en una quiebre barreras, convirtiéndose en un gran avance en las cuestiones ambientales mundiales, reconoció hasta hoy.

Palabras-Clave: Conferencias Ambientales. Educación Ambiental. Cuestión Ambiental.

\section{INTRODUÇÃO}

O ser humano constituiu-se historicamente como dependente e, concomitantemente, dominador dos recursos naturais. No entanto, esta dominação tem apresentado diversas problemáticas, visto que a questão ambiental envolve, além da dinâmica natural do ambiente, a sua interface com a sociedade (QUEIROZ, 2011).

A fim de resolver a questão ambiental, são implementadas, em escala global, ações integradas em uma rede de sujeitos e instituições promotoras da conscientização socioambiental mundial, uma vez que cada cidadão, independente das condições culturais, sociais e econômicas, mesmo que em escalas distintas de atuação, são responsáveis por repensar as ações regentes das relações homem/meio ambiente. Integrados, 
formarão em escala global, uma sociedade equilibrada e mantenedora das condições favoráveis ao contínuo desenvolvimento da vida na Terra.

Portanto, a conscientização é uma forma importante de lidarmos com as questões envolvendo a degradação da qualidade de vida e do meio ambiente. Tal conscientização só ocorrerá por meio da prática de Educação Ambiental (EA), junto à sociedade mundial.

As alterações ambientais promovidas por "[...] atividades humanas sempre aconteceram, mas atualmente as taxas dessas mudanças são cada vez maiores, e a capacidade dos humanos em modificar as paisagens também tem aumentado bastante" (GUERRA; MARÇAL, 2006, p. 38).

A questão ambiental envolve todas as pessoas, todavia, a reflexão acerca desta questão se realiza de maneira distinta entre os indivíduos, pois todos estão inseridos numa sociedade diversificada, seja de caráter cultural, econômico e/ou político, isto proporciona a formação de diferentes visões de mundo e, por conseguinte, há diversificadas formas de se conceber as relações socioambientais no mundo (QUEIROZ, 2009a).

A educação, por sua vez, é uma prática livre, histórica e socialmente constituída, em busca de valorizar as interrelações humanas, promovendo a humanização. Portanto, gera a dinamização das relações humanas e uma melhor compreensão do "mundo" no qual vivemos. Nesse sentido, o conceito de educação irá sofrer variações segundo o período histórico, a localização espacial e o grau de desenvolvimento técnico, científico e informacional na qual cada sociedade se insere (QUEIROZ, 2009b).

A educação participa do processo de transformação social de forma indireta, isto quer dizer: atua junto à consciência dos indivíduos, para estes reconhecerem as contradições presentes na sociedade, instrumentalizando-os a pensarem formas concretas de superação dessas contradições. Partindo do pressuposto da reflexão acerca da educação ser reflexão sobre os próprios indivíduos, podemos dizer que a educação auxilia no processo de transformação dos indivíduos. São estes que, por sua vez, desenvolverão as condições concretas da transformação social (CAMACHO, 2008; 2014; CAMACHO; FALCÃO, 2014).

A preocupação com as questões ambientais envolvem todas as sociedades, desde as mais desenvolvidas às mais arcaicas. Preocupação que não é recente, desde a "[...] antiguidade havia filósofos naturalistas e profetas, que se preocupavam com o homem e as suas interferências sobre o meio ambiente" (FRANÇA, 2006, p. 24).

Afiançando a informação anterior, Dias (1994, p. 20) destaca que:

Filósofos, cientistas, artistas, religiosos têm, ao longo da escalada do homem, expressado a sua admiração pela natureza, e a sua preocupação em protegê-la. As culturas orientais e a Grécia Clássica nos legaram reflexões filosóficas de grande sensibilidade a respeito das relações homemnatureza.

No entanto, é na segunda metade do século XX, década de 1960, que emerge no plano político mundial, uma série de movimentos sociais, dentre os quais o ecológico (PORTO-GONÇALVES, 2006). Destacando-se a publicação do texto "Os limites do Crescimento", publicado em Roma, no ano de 1968, o qual apresentou "[...] um amplo estudo sobre o consumo e as reservas dos recursos minerais e naturais e os limites de suporte/capacidade ambiental, ou a capacidade do planeta suportar desgastes e crescimento populacional" (CASCINO, 2007, p. 36). Já os primeiros eventos mundiais norteadores da Educação Ambiental, datam da década de 1970. 
A principal característica da evolução do movimento ambientalista se materializa por meio da prática da Educação Ambiental. Layrargues (2004, p. 07) define, em suas palavras, Educação Ambiental como "[...] o nome que historicamente se convencionou dar às práticas educativas relacionadas à questão ambiental".

\section{OBJETIVO}

Objetivamos com o presente trabalho fazer algumas considerações acerca do debate da Educação Ambiental presente nas principais conferências ambientais internacionais.

\section{METODOLOGIA}

Este artigo foi consolidado a partir de pesquisa bibliográfica sobre a questão ambiental, sobretudo, no que se refere as principais conferências ambientais internacionais que mencionam a educação ambiental em seus documentos finais. Buscamos, por meio dos documentos construídos a partir dessas conferências internacionais sobre meio ambiente, encontrar os elementos que impulsionaram o apoio às práticas de Educação Ambiental em escala mundial.

\section{AS CONFERÊNCIAS AMBIENTAIS INTERNACIONAIS E A EDUCAÇÃO AMBIENTAL}

Conferência de Estocolmo: Realizada em 1972 na cidade de Estocolmo, capital da Suécia, a Conferência da Organização das Nações Unidas sobre o Meio Ambiente, apresenta-se como um marco de grande relevância em relação à preocupação com a temática ambiental. Nessa ocasião, foi estabelecido como "Plano de Ação da Conferência de Estocolmo": a capacitação de professores e o desenvolvimento de novos métodos e recursos instrucionais para a Educação Ambiental (PEDRINI, 2000).

Conferência de Belgrado: A Conferência de Belgrado foi realizada em 1975 em Belgrado, na ex-lugoslávia, com o objetivo de discutir temáticas relacionadas à erradicação da pobreza; entre elas, a fome, o analfabetismo, a poluição, a exploração e dominação, assuntos que a serem abordados em um conjunto único e indissociável, em perpétua evolução. Como resultado, a Organização das Nações Unidas para a Educação, a Ciência e a Cultura - UNESCO, criou o Programa Internacional de Educação Ambiental - PIEA (PEDRINI, 2000).Conforme o estabelecido nessa conferência em seu documento final, Carta de Belgrado, é meta da Educação Ambiental:

Formar uma população mundial consciente e preocupada com o meio ambiente e com os problemas associados e que tenha conhecimento, aptidão, atitude, motivação e compromisso para trabalhar individual e coletivamente na busca de soluções para os problemas existentes e para prevenir novos. ([1975] 2007, não paginado).

Os objetivos da Educação Ambiental, de acordo com a Carta de Belgrado são:

Tomada de consciência. Ajudar às pessoas e aos grupos sociais a adquirir maior sensibilidade e consciência do meio ambiente em geral e dos problemas.

Conhecimentos. Ajudar às pessoas e aos grupos sociais a adquirir uma compreensão básica do meio ambiente em sua totalidade, dos problemas associados e da presença e função da humanidade neles, o que necessita uma responsabilidade crítica. 
Atitudes. Ajudar às pessoas e aos grupos sociais a adquirir valores sociais e um profundo interesse pelo meio ambiente que os impulsione a participar ativamente na sua proteção e melhoria.

Aptidões. Ajudar às pessoas e aos grupos sociais a adquirir as aptidões necessárias para resolver os problemas ambientais.

Capacidade de avaliação. Ajudar às pessoas e aos grupos sociais a avaliar as medidas e os programas de Educação Ambiental em função dos fatores ecológicos, políticos, sociais, estéticos e educativos.

Participação. Ajudar às pessoas e aos grupos sociais a desenvolver seu sentido de responsabilidade e a tomar consciência da urgente necessidade de prestar atenção aos problemas ambientais, para assegurar que sejam adotadas medidas adequadas. ([1975] 2007, não paginado).

Conferência de Tbilisi: Considerada o principal evento relacionado à discussão da temática Educação Ambiental, a Conferência de Tbilisi (Conferência Intergovernamental de Educação Ambiental) foi realizada entre os dias 14 e 26 de outubro de 1977, na Geórgia (ex-URSS), sob a orientação da Organização das Nações Unidas para a Educação, a Ciência e a Cultura e com a colaboração do Programa das Nações Unidas para o Meio Ambiente - PNUMA (PEDRINI, 2000).

Pedrini (2000, p. 28) aponta os principais pontos vislumbrados na Conferência de Tbilisi, que seguem:

[...] Deveria a [Educação Ambiental] basear-se na ciência e tecnologia para a consciência e adequada apreensão dos problemas ambientais, fomentando uma mudança de conduta quanto à utilização dos recursos ambientais. Deveria se dirigir tanto pela educação formal como informal a pessoas de todas as idades. Despertar o indivíduo a participar ativamente na solução de problemas ambientais do seu cotidiano. Teria que ser permanente, global e sustentada numa base interdisciplinar, demonstrando a dependência entre as comunidades nacionais, estimulando a solidariedade entre os povos da Terra. [...]

\section{Quanto ao conceito de Educação Ambiental, segundo a Declaração de Tbilisi:}

A Educação Ambiental é o resultado de uma reorientação e articulação de diversas disciplinas e experiências educativas que facilitam a percepção integrada do meio ambiente, tornando possível uma ação mais racional e capaz de responder às necessidades sociais. ([1977] 2008, não paginado).

Com relação ao público alvo, a Declaração de Tbilisi assevera:

A Educação Ambiental deve ser dirigida à comunidade despertando o interesse do indivíduo em participar de um processo ativo no sentido de resolver os problemas dentro de um contexto de realidades específicas, estimulando a iniciativa, o senso de responsabilidade e o esforço para construir um futuro melhor. Por sua própria natureza, a Educação Ambiental pode, ainda, contribuir satisfatoriamente para a renovação do processo educativo. ([1977] 2008, não paginado).

\section{Com referência à Educação Ambiental, a Declaração de Tbilisi apresenta que:}

A Educação Ambiental deve abranger pessoas de todas as idades e de todos os níveis, no âmbito do ensino formal e não-formal. Os meios de comunicação social têm a grande responsabilidade de colocar seus enormes recursos a serviço dessa missão educativa. Os especialistas no assunto, e também aqueles cujas ações e decisões podem repercutir significativamente no meio ambiente, deverão receber, no decorrer da sua formação, os conhecimentos e atitudes necessários, além de detectarem plenamente o sentido de suas responsabilidades nesse aspecto. ([1977] 2008, não paginado).

A respeito dos objetivos da Educação Ambiental, a Declaração de Tbilisi afirma que: 
Com esse propósito, cabe à Educação Ambiental dar os conhecimentos necessários para interpretar os fenômenos complexos que configuram o meio ambiente; fomentar os valores éticos, econômicos e estéticos que constituem a base de uma autodisciplina, que favoreçam o desenvolvimento de comportamentos compatíveis com a preservação e melhoria desse meio ambiente, assim como uma ampla gama de habilidades práticas necessárias à concepção e aplicação de soluções eficazes aos problemas ambientais. ([1977] 2008, não paginado).

Para finalizar, a Declaração de Tbilisi:

\begin{abstract}
Convoca os Estados-membros a incluírem em suas políticas de educação, medidas visando incorporar um conteúdo, diretrizes e atividades ambientais em seus sistemas, com base nos objetivos e características mencionadas anteriormente. Convida as autoridades educacionais a intensificarem seu trabalho de reflexão, pesquisa e inovação no que tange à Educação Ambiental. Incentiva os Estados-membros a colaborar nessa área, principalmente através do intercâmbio de experiências, pesquisas, documentação e materiais, colocando, além disso, os serviços de formação à disposição do corpo docente e dos especialistas de outros países. Estimula, finalmente, a comunidade internacional a dar uma generosa ajuda para fortalecer essa colaboração numa área de atuação que simboliza a necessária solidariedade de todos os povos, e que pode considerar-se como particularmente alentadora na promoção do entendimento internacional e da causa da paz. ([1977] 2008, não paginado).
\end{abstract}

Conferência de Moscou: Realizada em agosto de 1987, em Moscou, na ex-União Soviética - URSS, atual Rússia, a Conferência de Moscou obteve a participação de aproximadamente trezentos profissionais da educação vindos de uma centena de países. Dele resultou um documento denominado Estratégia Internacional de Ação em Matéria de Educação e Formação ambiental para o Decênio de 1990 (ASSIS, 1990; PEDRINI, 2000).

O documento é composto de informações, ideias, estudos e pesquisas internacionais de projetos piloto e investigações, conclusões de reuniões internacionais realizadas desde 1975. Apresenta elementos para uma estratégia internacional de ação em matéria de educação e formação ambiental para o Decênio de 1990. Mostra os princípios e características essenciais da educação e da formação ambientais (ASSIS, 1990). Para Pedrini (2000, p. 29):

\begin{abstract}
A [Educação Ambiental] nesta conferência não governamental reforçou os conceitos consagrados pela de Tbilisi. A [Educação Ambiental] deveria preocupar-se tanto com a promoção da conscientização e transmissão de informações, como com o desenvolvimento de hábitos e habilidades, promoção de valores, estabelecimento de critérios e padrões e orientações para a resolução de problemas e tomada de decisões. Portanto, objetivar modificações comportamentais nos campos cognitivo e afetivo.
\end{abstract}

As prioridades advindas da Conferência de Moscou tinham como meta principal propor uma estratégia internacional de ação em matéria de educação e formação ambiental para a década de 1990. Conforme identificado por Pedrini (2000, p. 29-30), foi:

Desenvolvimento de um modelo curricular. Intercâmbio de informações sobre o desenvolvimento de currículo. Desenvolvimento de novos recursos instrucionais. Promoção de avaliações de currículos. Capacitar docentes e licenciandos em Educação Ambiental. Capacitar alunos de cursos profissionalizantes, priorizando o de turismo pela sua característica internacional. Melhorar a qualidade das mensagens ambientais veiculadas pela mídia ao grande público. Criar um banco de programas audiovisuais. Desenvolver museus interativos. Capacitar especialistas ambientais através de pesquisa. Utilizar unidades de conservação ambiental na capacitação regional de especialistas. Promover a consultoria interinstitucional em âmbito internacional. Informar sobre a legislação 
ambiental; dentre outras medidas não menos importantes.

Conferência de Jomtien: Realizou-se na Tailândia no ano de 1990, a "Conferência Mundial sobre Ensino para Todos, Satisfação das necessidades básicas de aprendizagem", tendo como resultado o documento conhecido como "Declaração Mundial sobre Educação para Todos". Em seu texto, esse documento, enfatiza a necessidade de todas as nações viabilizarem para suas respectivas populações o direito e a acessibilidade à educação, além da melhoria de sua qualidade, visto uma grande parcela da população mundial viver excluída do sistema educacional, e outra grande parcela, quando inclusa, usufrui de uma educação de qualidade bastante questionável.

Reforçando ideia anterior, a "Declaração Mundial sobre Educação para Todos" traz que naquele momento:

Mais de 100 milhões de crianças, das quais pelo menos 60 milhões são meninas, não têm acesso ao ensino primário. Mais de 960 milhões de adultos - dois terços dos quais mulheres são analfabetos, e o analfabetismo funcional é um problema significativo em todos os países industrializados ou em desenvolvimento; - mais de um terço dos adultos do mundo não têm acesso ao conhecimento impresso, às novas habilidades e tecnologias, que poderiam melhorar a qualidade de vida e ajudálos a perceber e a adaptar-se às mudanças sociais e culturais. Mais de 100 milhões de crianças e incontáveis adultos não conseguem concluir o ciclo básico, e outros milhões, apesar de concluí-lo, não conseguem adquirir conhecimentos e habilidades essenciais. (UNESCO, 1998, não paginado).

Concomitantemente com a situação expressa anteriormente, a sociedade global vem enfrentando, conforme o mesmo texto:

[...] um quadro sombrio de problemas, entre os quais: o aumento da dívida de muitos países, a ameaça de estagnação e decadência econômicas, o rápido aumento da população, as diferenças econômicas crescentes entre as nações e dentro delas, a guerra, a ocupação, as lutas civis, a violência; a morte de milhões de crianças que poderia ser evitada e a degradação generalizada do meio-ambiente. Esses problemas atropelam os esforços envidados no sentido de satisfazer as necessidades básicas de aprendizagem, enquanto a falta de educação básica para significativas parcelas da população impede que a sociedade enfrente esses problemas com vigor e determinação. (UNESCO, 1998, não paginado).

Segundo Declaração Mundial sobre Educação para Todos "[...] a educação pode contribuir para conquistar um mundo mais seguro, mais sadio, mais próspero e ambientalmente mais puro, e que, ao mesmo tempo, favoreça o progresso social, econômico e cultural, a tolerância e a cooperação internacional". Ainda nessa perspectiva, a mesma alerta que:

\begin{abstract}
A satisfação dessas necessidades confere aos membros de uma sociedade a possibilidade e, ao mesmo tempo, a responsabilidade de respeitar e desenvolver sua herança cultural, linguística e espiritual, de promover a educação de outros, de defender a causa da justiça social, de proteger o meio-ambiente e de ser tolerante com os sistemas sociais, políticos e religiosos que difiram dos seus, assegurando respeito aos valores humanistas e aos direitos humanos comumente aceitos, bem como de trabalhar pela paz e pela solidariedade internacionais em um mundo interdependente. (UNESCO, 1998, não paginado).
\end{abstract}

Assim, compreender-se que:

Um compromisso efetivo para superar as disparidades educacionais deve ser assumido. Os grupos excluídos - os pobres; os meninos e meninas de rua ou trabalhadores; as populações das periferias 
urbanas e zonas rurais; os nômades e os trabalhadores migrantes; os povos indígenas; as minorias étnicas, raciais e linguísticas; os refugiados; os deslocados pela guerra; e os povos submetidos a um regime de ocupação - não devem sofrer qualquer tipo de discriminação no acesso às oportunidades educacionais. (UNESCO, 1998, não paginado).

Somente a partir da humanização proporcionada por uma educação inclusiva de qualidade será possível combater, de maneira abrangente, o processo de analfabetismo ambiental, que aflige a grande maioria da população mundial.

Conferência do Rio de Janeiro (RIO-92 ou ECO-92): Conferência da Organização das Nações Unidas - ONU, sobre Meio Ambiente e Desenvolvimento, RIO-92 ou ECO-92 foi realizada na cidade do Rio de Janeiro, Brasil, no ano de 1992. Primack; Rodrigues (2001, p. 289) destacam "[...] um aspecto digno de nota da conferência foi enfatizar o vínculo que existe entre a proteção do meio ambiente e a necessidade de aliviar a pobreza do Terceiro Mundo, através do aumento do volume de ajuda financeira por parte dos países ricos". Resultaram dessa conferência dois documentos de grande relevância para a Educação Ambiental. 0 primeiro é a Declaração sobre Meio Ambiente e Desenvolvimento, no qual há 27 princípios que buscam reafirmar a Declaração da Conferência das Nações Unidas sobre o Meio Ambiente Humano, adotada em Estocolmo em 16 de junho de 1972. O seu texto afirma ter por objetivo: "[...] estabelecer uma nova e justa parceria global por meio do estabelecimento de novos níveis de cooperação entre os Estados, os setoreschave da sociedade e os indivíduos [...]". ([1992] 2015, não paginado). O segundo documento resultante da Conferência do Rio de Janeiro é a Agenda 21, a qual se configurou como um grande avanço frente às questões ambientais, pois aborda em seu texto as preocupações na promoção do desenvolvimento sustentável. "A Agenda $\mathbf{2 1}$ pode ser definida como um instrumento de planejamento para a construção de sociedades sustentáveis, em diferentes bases geográficas, que concilia métodos de proteção ambiental, justiça social e eficiência econômica". ([1992] 2007, não paginado, grifo do autor).

Conferência de Nova Delhi: A Conferência de Nova Delhi foi realizada no ano de 1993, na cidade de Nova Delhi, na Índia, o segundo país mais populoso do mundo, superado atualmente apenas pela China, e onde problemas de caráter sociocultural e ambiental afligem a grande maioria da população.

A Declaração de Nova Delhi sobre Educação para Todos, constitui-se em um documento formalizado por nove países considerados em desenvolvimento e, ao mesmo tempo, mais populosos do mundo, são eles a Indonésia, China, Bangladesh, Brasil, Egito, México, Nigéria, Paquistão e Índia. Reconhecendo em seu texto a importância de:

Os conteúdos e métodos de educação precisam ser desenvolvidos para servir às necessidades básicas de aprendizagem dos indivíduos e das sociedades, proporcionando-lhes o poder de enfrentar seus problemas mais urgentes - combate à pobreza, aumento da produtividade, melhora das condições de vida e proteção ao meio ambiente - e permitindo que assumam seu papel por direito na construção de sociedades democráticas e no enriquecimento de sua herança cultural. (UNESCO, [1998] 2008, não paginado).

A Conferência de Nova Delhi possui grande importância no processo de democratização da educação em nível mundial, uma vez que mais de $50 \%$ da população mundial vivem nos nove países a assiná-la a "Declaração de Nova Delhi sobre Educação para Todos", daí a grande importância e representatividade desse documento perante a sociedade global. Espera-se é que esse valor também seja percebido pelos países já desenvolvidos e economicamente habilitados para contribuir na efetivação desses direitos estabelecidos em conferências, mas ainda por enfrentar. Neste contexto, o documento termina enfatizando: 
[...] mobilizaremos todos os setores de nossas sociedades em prol da educação para todos, endossando por este instrumento o Projeto de Ação que acompanha esta Declaração e nos comprometendo a revisar nosso progresso a nível nacional e a compartilhar nossas experiências entre nós e com a comunidade global. (UNESCO, [1998] 2008, não paginado).

Conferência de Thessaloniki: Realizou-se na cidade grega de Tessaloniki, no ano de 1997, a Conferência Internacional em Ambiente e Sociedade: Educação e Conscientização Pública para a Sustentabilidade.

Conforme traz a Declaração de Thessaloniki participaram desta conferência, a qual se realizou com o apoio da Organização das Nações Unidas para a Educação, a Ciência e a Cultura e do governo grego, "organizações governamentais, inter-governamentais, e não-governamentais - ONGs, e a sociedade civil de mais de 83 países". Documento este considerado um marco para o desenvolvimento sustentável mundial. Acerca da Educação Ambiental, o documento traz o reconhecimento da importância dos eventos anteriores e acrescenta:

As recomendações e planos de ação da Conferência de Belgrado em Educação Ambiental (1975), a Conferência Inter-governamental de Tbilisi sobre Educação Ambiental (1977), a Conferência de Moscou sobre Educação Ambiental e Treinamento (1987) e o Congresso Mundial de Toronto sobre Educação e Comunicação em Ambiente e Desenvolvimento (1992), são válidas e ainda não totalmente exploradas. ([1997] 2008, não paginado).

Neste contexto, o documento propõe: “[...] uma educação apropriada e a conscientização pública devem ser reconhecidas como os pilares da sustentabilidade, juntamente com a legislação, a economia e a tecnologia". ([1997] 2008, não paginado).

As duas conferências abordadas na sequência, apesar de serem eventos cujos objetivos não buscaram discutir especificamente o tema Educação Ambiental, são classificados como importantes do ponto de vista de vislumbrar o controle da emissão de gases provenientes, principalmente da queima de combustíveis fósseis e de vegetais, seja pela produção do carvão vegetal ou pelo desmatamento, colocando em debate a questão do aquecimento da atmosfera terrestre ${ }^{1}$. Dessa forma, essas duas Conferências se preocupam diretamente com um dos problemas ambientais mais discutidos internacionalmente na atualidade.

Conferência de Quioto: Realizada no ano de 1997, na cidade japonesa de Quioto, esta conferência não buscou discutir diretamente o tema Educação Ambiental, mas apresentou como tema central de discussão a redução dos gases diretamente responsáveis pelo fenômeno do efeito estufa, consequentemente, do aquecimento global. Ressaltam-se os apontamentos de Alves (2001) apud Bissaco; Souza (2005, p. 4531) relatando que durante a Conferência de Quioto "[...] 178 países assinaram um acordo para a redução das emissões de gases-estufa (especialmente o $\mathrm{CO}_{2}$ ) [...]". Documento conhecido como Protocolo de Quioto, o qual destaca em seu texto:

Cerca de 10.000 delegados, observadores e jornalistas participaram desse evento de alto nível realizado em Quioto, Japão, em dezembro de 1997. A conferência culminou na decisão por consenso de adotar-se um Protocolo segundo o qual os países industrializados reduziriam suas emissões combinadas de gases de efeito estufa em pelo menos $5 \%$ em relação aos níveis de 1990 até o período entre 2008 e 2012. Esse compromisso, com vinculação legal, promete produzir uma reversão da tendência histórica de crescimento das emissões iniciadas nesses países há cerca de 150 anos.

\footnotetext{
${ }^{1}$ Salientamos que não temos a intenção neste texto, de aprofundar este debate que é controverso ainda do ponto de vista teóricopolítico-ideológico-metodológico.
} 
O Art. 2을 desse Protocolo destaca que as partes envolvidas nesse acordo assumem a responsabilidade de promover o desenvolvimento sustentável. Contribuindo para que haja promoção de um meio ambiente mais equilibrado e seguro. E o seu Art. 10 destaca a importância da ocorrência de colaboração mútua, tanto pública quanto privada na troca de informações e tecnologias ou de facilidades de financiamento. Conforme se pode observar:

[...] na promoção de modalidades efetivas para o desenvolvimento, a aplicação e a difusão, e tomar todas as medidas possíveis para promover, facilitar e financiar, conforme o caso, a transferência ou o acesso a tecnologias, know-how, práticas e processos ambientalmente seguros relativos à mudança do clima, em particular para os países em desenvolvimento, incluindo a formulação de políticas e programas para a transferência efetiva de tecnologias ambientalmente seguras que sejam de propriedade pública ou de domínio público e a criação, no setor privado, de um ambiente propício para promover e melhorar a transferência de tecnologias ambientalmente seguras e o acesso a elas.

Além de pregar a promoção de melhorias nas políticas públicas referentes ao meio ambiente e estimular sua discussão, propõe o intercâmbio de informações com vistas à cooperação internacional nos programas educacionais. De acordo com o que segue:

Cooperar e promover em nível internacional e, conforme o caso, por meio de organismos existentes, a elaboração e a execução de programas de educação e treinamento, incluindo o fortalecimento da capacitação nacional, em particular a capacitação humana e institucional e o intercâmbio ou cessão de pessoal para treinar especialistas nessas áreas, em particular para os países em desenvolvimento, e facilitar em nível nacional a conscientização pública e o acesso público a informações sobre a mudança do clima.

Conferência do Rio de Janeiro (Rio+20): A última conferência foi a Conferência das Nações Unidas sobre Desenvolvimento Sustentável, Rio+20, que foi realizada entre os dias 13 e 22 de junho de 2012, na cidade do Rio de Janeiro, no Brasil. Esta conferência foi denominada de Rio+20 por marcar os vinte anos de realização da Conferência das Nações Unidas sobre Meio Ambiente e Desenvolvimento (Rio-92) contribuiu para definir uma agenda a respeito do desenvolvimento sustentável em duas décadas. O objetivo da Conferência foi a renovação do compromisso político com o desenvolvimento sustentável. Tendo dois temas principais:a economia verde no contexto do desenvolvimento sustentável e da erradicação da pobreza; e a estrutura institucional para o desenvolvimento sustentável (BRASIL, 2015).

No tocante à educação, o documento final da conferência dedica um tópico específico dividido em 4 parágrafos no sentido de relacionar a importância da educação com o desenvolvimento sustentável. A proposta é que o tema entre no currículo da educação básica e do ensino superior. Vejamos o que diz o documento:

Nós reconhecemos que o acesso de todos à educação de qualidade é uma condição essencial para o desenvolvimento sustentável e à inclusão social. Nos comprometemos com o fortalecimento da contribuição de nossos sistemas de educação na busca do desenvolvimento sustentável, inclusive através de um melhor treinamento e desenvolvimento curricular dos educadores.

Nós convocamos as universidades a se tornarem modelos das melhores práticas e transformação ao dar um exemplo de sustentabilidade de suas instalações em seus campi e ensinando desenvolvimento sustentável como um módulo em todos os cursos. Desse modo, práticas sustentáveis se tornarão uma parte integrante do aprendizado e da ação. ([2012] 2015, p. 17). 
O documento também cita o incentivo ao intercâmbio internacional e à criação de bolsas de pesquisa na área de educação para o desenvolvimento sustentável. Sendo esta temática de caráter inter-multidisciplinar no sentido de desenvolver um conhecimento holístico, que compreenda a realidade em sua totalidade.

\begin{abstract}
Nós encorajamos atividades de intercâmbio internacional de educação para o desenvolvimento sustentável, incluindo a criação de bolsas de estudo e de pesquisa para estudos internacionais em disciplinas campos e interdisciplinares pertinentes à promoção do desenvolvimento sustentável. Nós concordamos em promover a educação para o desenvolvimento sustentável para além da Década de Educação da ONU para o Desenvolvimento Sustentável em 2014, para educar uma nova geração de estudantes nos valores, disciplinas-chave e abordagens holísticas e multidisciplinares essenciais para a promoção do desenvolvimento sustentável. ([2012] 2015, p. 17).
\end{abstract}

\title{
CONSIDERAÇÕES FINAIS
}

O grande avanço acerca das preocupações ambientais e, por consequência, do movimento ambientalista se materializou na segunda metade do século $X X$, no pós-segunda guerra mundial, principalmente por meio dos seguintes eventos: Conferência de Estocolmo, Conferência de Belgrado, Conferência de Tbilisi, Conferência de Moscou, Conferência de Jomtien, Conferência do Rio de Janeiro, Conferência de Nova Delhi, Conferência de Thessaloniki, Conferência de Quioto e Rio+20. Sendo que a Conferência de Estocolmo, realizada em 1972, apresentou-se como um momento de sensível evolução da preocupação das questões ambientais, tornando-se, portanto, o desencadeador do debate concernente às questões ambientais mundiais, reconhecida até os dias atuais.

A preocupação com a Educação, perpassa quase a totalidade dessas conferências, dependendo o tempoespaço, essa inquietação foi maior ou menor. Entendemos ser esta uma questão controversa ainda sob o ponto de vista teórico-político-ideológico, tendo em vista as conferências trazerem perspectivas, muitas vezes, divergentes entre empresas, Estados e movimentos sociais ambientalistas. Tendo em vista que o objetivo desse texto teve um caráter mais descritivo que de aprofundamento dessas questões, não mergulhamos na trama das contradições e nas disputas inerentes ao debate da sustentabilidade. Mas, fica clara a posição a favor de uma Educação Ambiental mais crítica e transformadora. Que se preocupe com a totalidade complexa da relação sociedade-natureza. Lembrando que a apropriação predatória da natureza não pode ser discutida separadamente das relações sociais capitalistas cuja essência é a exploração máxima tanto humana quanto da natureza. Estes são fundamentos que precisam ficar mais claros nas conferências mundiais acerca do meio ambiente, bem como, numa proposta crítica-transformadora de Educação Ambiental.

\section{REFERÊNCIAS BIBLIOGRÁFICAS}

AGENDA 21. Ministério do meio ambiente, dos recursos hídricos e da Amazônia Legal. Disponível em: <http://www.mma.gov.br/index.php?ido=conteudo.monta\&idEstrutura=18\&idConteudo=575>. Acesso em: 18 jul. 2007.

ASSIS, E. S. de. A UNESCO e a Educação Ambiental. Em Aberto, Brasília/DF, v. 10, n. 49, jan./mar. 1991. 
BISSACO, J. Z.; SOUZA, J. J. L. L. de. As incertezas sobre o aquecimento global e as dificuldades de implementação do Protocolo de Quioto: uma revisão bibliográfica. In: XI Simpósio Brasileiro de Geografia Física Aplicada. 2005, São Paulo/SP, Anais... São Paulo/SP: USP, 2005.

BRASIL. Sobre a Rio+20. Disponível em: <http://www.rio20.gov.br/sobre_a_rio_mais_20.html>. Acesso em: 10 fev. 2015.

CAMACHO, R. S.; FALCÃO, A. Na trilha da Educação Ambiental emancipatória: pegadas conceituais e clareiras experienciais In: DIAS, L. S. (Org.). Educação Ambiental em foco. Tupã/SP: ANAP, 2014.p. 17-41.

CAMACHO, R. S. O ensino da geografia e a questão agrária nas séries iniciais do ensino fundamental. 2008. 462 f. Dissertação (Mestrado em Geografia) - Universidade Federal de Mato Grosso do Sul, Aquidauana/MS, 2008.

CAMACHO, R. S. Paradigmas em disputa na educação do campo. 2014. 802 f. Tese (Doutorado em Geografia) Faculdade de Ciências e Tecnologia, Universidade Estadual Paulista, Presidente Prudente/SP, 2014.

CASCINO, F. Educação ambiental: princípios, história e formação de professores. 4.ed. São Paulo/SP: SENAC, 2007.

CARTA DE BELGRADO. Uma estrutura global para a educação ambiental. Disponível em:

<http://www.mma.gov.br/port/sdi/ea/deds/pdfs/crt_belgrado.pdf>. Acesso em: 23 nov. 2007.

DECLARAÇÃO DE THESSALONIKI. Disponível em: <http://www.mma.gov.br/port/sdi/ea/deds/pdfs/declthess aloniki.pdf $>$. Acesso em: 23 nov. 2007.

DECLARAÇÃO DO RIO DE JANEIRO SOBRE MEIO AMBIENTE E DESENVOLVIMENTO (1992). Disponível em: <http://www.mma.gov.br/port/sdi/ea/documentos/convs/decl_rio92.pdf>. Acesso em: 05 fev. 2015.

DECLARAÇÃO DE TBILISI. Algumas Recomendações da Conferência Intergovernamental sobre Educação Ambiental aos Países Membros. Tbilisi, CEI, de 14 a 26 de outubro de 1977). Disponível

em:<http://educacao.riodasostras.rj.gov.br/rearo/pdf/decltbilisi.pdf> Acesso em: 25 jan. 2008.

DECLARAÇÃO SOBRE MEIO AMBIENTE E DESENVOLVIMENTO. Disponível em: <http://www.direitoshumanos .usp.br/index.php/Meio-Ambiente/declaracao-sobre-meio-ambiente-e-desenvolvimento.html>. Acesso em: 25 jan. 2008.

DIAS, G. F. Educação ambiental: princípios e práticas. 3 ed. São Paulo/SP: Gaia, 1994.

FRANÇA, C. M. A educação ambiental na escola: um estudo sobre as representações sociais dos professores do ensino fundamental do município de Pouso Redondo - SC. 2006. 124 f. Dissertação (Mestrado em Educação) - Universidade do Oeste de Santa Catarina, Joaçaba/SC, 2006.

GUERRA, A. J. T; MARÇAL, M. Geomorfologia ambiental. Rio de Janeiro/RJ: Bertrand, 2006.

LAYRARGUES, P. P. (Re) conhecendo a educação ambiental brasileira. In: LAYRARGUES, P. P., (Coord.). Identidades da educação ambiental brasileira. Brasília/DF: MMA, 2004.

ONU. Rio + 20 - Conferência das Nações Unidas sobre desenvolvimento sustentável: o futuro que queremos. Rio de Janeiro: ONU, 2012. Disponível em: <http://www.rio20.gov.br/documentos/documentos-da-conferencia/esbocozero.html>. Acesso em: 10 fev. 2015.

PEDRINI, A. de G. Trajetória da educação ambiental. In: PEDRINI, A. de G., (Org.). Educação ambiental: reflexões e práticas contemporâneas. 3 ed. Petrópolis/RJ: Vozes, 2000.

PORTO-GONÇALVES, C. W. Os (des) caminhos do meio ambiente. 14 ed. São Paulo/SP: Contexto, 2006. 
PRIMACK, R. B.; RODRIGUES, E. Biologia da conservação. Londrina/PR: Planta, 2001.

PROTOCOLO DE QUIOTO. Disponível em: <http://www.direitoshumanos.usp.br/index.php/Meio-Ambiente/protocolode-quioto-a-convencao-quadro-das-nacoes-unidas-sobre-mudanca-do-clima.html>. Acesso em: 25 jan. 2008.

QUEIROZ, F. L. L. A educação ambiental e a formação de professores. In: VIII ENCONTRO NACIONAL DA ASSOCIAÇÃO NACIONAL DE PÓS-GRADUAÇÃO E PESQUISA EM GEOGRAFIA. 2009, Curitiba/PR, Anais...Curitiba/PR: UFPR,2009a.

QUEIROZ, F. L. L. Considerações sobre a educação ambiental no Brasil. In: ENCONTRO NACIONAL DE GRUPOS PET GEOGRAFIA, 4, 2009, Três Lagoas/MS, Anais...Três Lagoas/MS: UFMS,2009b.

QUEIROZ, F. L. L. Aspectos da dinâmica hidrossedimentológica e do uso e ocupação do solo na bacia do Córrego Arapuá (MS). 2011. 125 f. Dissertação (Mestrado em Geografia) - Universidade Federal de Mato Grosso do Sul, Três Lagoas/MS, 2011.

UNESCO. Declaração Mundial sobre Educação para Todos: satisfação das necessidades básicas de aprendizagem. Jomtien, 1990. Jomtien: UNESCO, 1998.

UNESCO. Declaração de Nova Delhi sobre Educação Para Todos. Nova Dehli, 6 de dezembro de 1993. Nova Dehli: UNESCO, 1998. Disponível em: <http://unesdoc.unesco.org/images/0013/001393/139393por.pdf>. Acesso em: 25 jan. 2008. 